\title{
Tsunami propagation modelling - a sensitivity study
}

\author{
M. H. Dao and P. Tkalich \\ Tropical Marine Science Institute, National University of Singapore, Singapore
}

Received: 23 May 2007 - Revised: 9 October 2007 - Accepted: 1 November 2007 - Published: 3 December 2007

\begin{abstract}
Indian Ocean (2004) Tsunami and following tragic consequences demonstrated lack of relevant experience and preparedness among involved coastal nations. After the event, scientific and forecasting circles of affected countries have started a capacity building to tackle similar problems in the future. Different approaches have been used for tsunami propagation, such as Boussinesq and Nonlinear Shallow Water Equations (NSWE). These approximations were obtained assuming different relevant importance of nonlinear, dispersion and spatial gradient variation phenomena and terms. The paper describes further development of original TUNAMI-N2 model to take into account additional phenomena: astronomic tide, sea bottom friction, dispersion, Coriolis force, and spherical curvature. The code is modified to be suitable for operational forecasting, and the resulting version (TUNAMI-N2-NUS) is verified using test cases, results of other models, and real case scenarios. Using the 2004 Tsunami event as one of the scenarios, the paper examines sensitivity of numerical solutions to variation of different phenomena and parameters, and the results are analyzed and ranked accordingly.
\end{abstract}

\section{Introduction}

Transoceanic tsunami waves have typical length of hundreds of kilometers and amplitude of less than a meter in deep oceans. Comparing with the ocean depth of a few thousand meters, tsunamis are classified as shallow water waves. Due to a balanced contribution of nonlinear and dispersion forces, tsunamis can propagate a long distance through an entire ocean with a little loss of energy, while bottom friction over uneven shallow ocean bathymetry may partially absorb

Correspondence to: M. H. Dao

(tmsdmh@nus.edu.sg) energy of the propagating waves. Additionally, astronomic tides and Coriolis force may affect tsunami dynamics.

It is important to know a comparable contribution of these and other relevant phenomena on tsunami propagation. Weisz and Winter (2005) showed that the change of depth caused by tides should not be neglected in tsunami run-up calculation. Kowalik et al. (2006), Myers and Baptista (2001) included tide in the governing equations to investigate the dynamics related to the nonlinear interaction with tide leading to amplification of tsunami height and currents in the coastal region. For studying dispersive effects on tsunami wave propagation, Shuto (1991) compared numerical results of three long wave theories in deep water: linear Boussinesq, Boussinesq and linear long wave. The author pointed out that linear Boussinesq and Boussinesq equations almost coincide with the true solution (given by the linear surface wave theory, which fully includes the dispersion effect), suggesting that the nonlinear term is not important in the tsunami propagation in deep water. An interesting conclusion from his study is that numerical dispersion in coarser grid made the solution better than higher-order model with the same grid length and even the same model at finer grid. Recently, Grilli et al. (2007) compared numerical results of NSWE and Boussinesq simulations for the Indian Ocean (2004) Tsunami. Their study showed a remarkable difference of surface elevation $(\sim 20 \%)$ west of the source, in deep water. Horrillo and Kowalik (2006) did comparisons of tsunami propagation modeling using NSWE, nonlinear Boussinesq equations (NLB) and full Navier-Stokes equations aided by the Volume-Of-Fluid method (FNS-VOF). The authors concluded that all approaches agreed well; dispersion effect becomes more noticeable as time advances; and NLB and FNSVOF reproduce better small features in the leading wave. However, the computation time of NLB is much longer than NWSE, and FNS-VOF codes are even slower than NLB.

Effect of friction on tsunami propagation was studied in Myers and Baptista (2001) for the Hokkaido Nansei-Oki

Published by Copernicus Publications on behalf of the European Geosciences Union. 


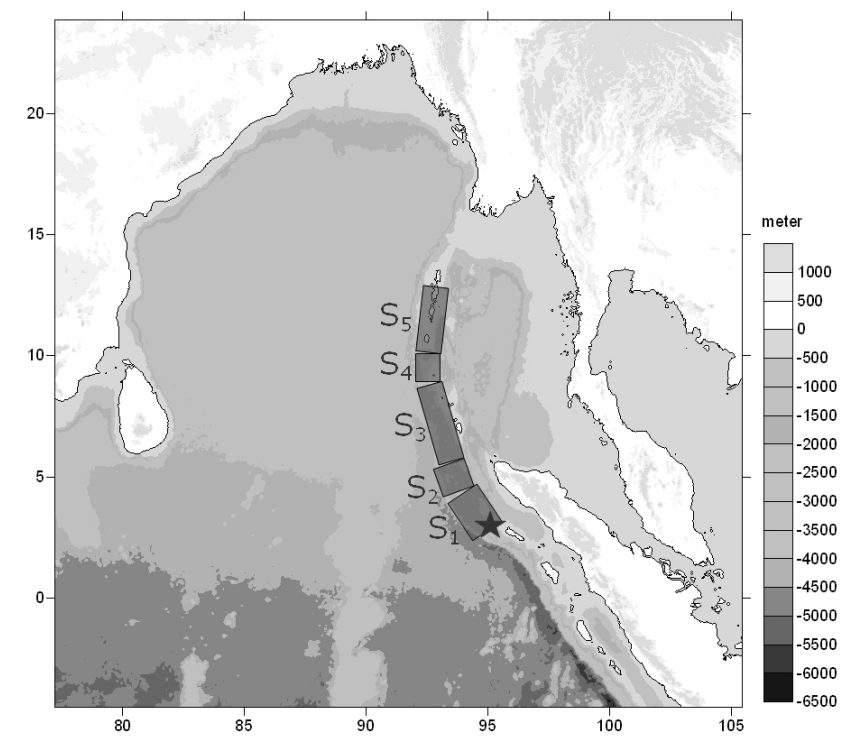

Fig. 1. Bathymetry and topography for computational domain and the fault segments S1-S5 ( $\star$ is the location of earthquake epicentre).

event. They used Manning coefficient with three different values $(0.015,0.0275$ and 0.035$)$, and a different friction parameterization. Root mean square differences plotted against water depth show that most of the larger differences are occurred in $0-10 \mathrm{~m}$ depth. Significant differences are also observed on inundated land. The range of maximum run-up difference is from -6 to $+6 \mathrm{~m}$ indicated that choosing friction coefficient definitely influences the calculation of wave run-up on land.

The effect of Coriolis force on transoceanic tsunami was considered by Shuto (1991) and Kowalik and Murty (1989). Shuto (1991) simulated the 1969 Chilean Tsunami with and without Coriolis terms. Result shows differences in wave height but not much difference in arrival time. Kowalik and Murty (1989) concluded that the Coriolis force has a little influence on small period waves, but distinctive difference in the amplitude observed on the large period waves. They expected that tsunamis along the shelf could be modified by the Coriolis force more, because of the large period waves occurred there.

Spherical curvature of the Earth surface needs to be considered in the governing equations for far-field tsunami simulation; however, the phenomenon was often neglected in earlier tsunami numerical codes.

In this paper, different modifications of well known tsunami propagation model TUNAMI-N2 (Goto et al., 1997) are developed to explore the sensitivity of the computational results to the variation of major model parameters. To take into account the Earth's curvature in the case of propagation of transoceanic tsunami, the NSWE model is formulated in spherical coordinates. Several other modifications are made to the original TUNAMI-N2 code in order to study the effects of tide, bottom friction, Coriolis, spherical coordinate, nonlinearity and dispersion on the wave propagation. Model sensitivity to variation of other parameters, such as bathymetry, numerical methods, computational grid type, and source characteristics were considered elsewhere; and therefore they are not studied in the paper. The version of TUNAMI-N2 code that uses NSWE in spherical coordinates with Coriolis terms serves as a control model, and computed maximum tsunami amplitude is compared with the control model. The case study of Indian Ocean Tsunami (2004) event utilizes source estimation by Grilli et al. (2007) with minor changes to find the best fit.

\section{The tsunami model}

The model TUNAMI-N2 used in this paper was originally authored by Professor Fumihiko Imamura in Disaster Control Research Center in Tohoku University (Japan) through the Tsunami Inundation Modeling Exchange (TIME) program. TUNAMI-N2 is one of the key tools to study propagation and coastal amplification of tsunamis in relation to different initial conditions (Goto and Ogawa, 1982; Imamura and Goto, 1988; Imamura and Shuto, 1989; Goto et al., 1997, Shuto and Goto, 1988; Shuto et al., 1990). The program can compute the water surface elevation and velocities due to tsunami across entire computational domain, including shallow and land regions. TUNAMI-N2 code was implemented to simulate tsunami propagation and run-up in Pacific, Atlantic and Indian Oceans, with zoom-in at particular areas of Japanese, Caribbean, Russian, and Mediterranean seas (Yalciner et al., 2000, 2001, 2002, 2004; Zahibo et al., 2003; Tinti et al., 2006).

\subsection{Governing equations}

TUNAMI-N2 uses second-order explicit leap-frog finite difference scheme to discretize a set of NSWE. For the propagation of tsunami in the shallow water, the horizontal eddy turbulence terms are negligible as compared with the bottom friction. The equations are written in Cartesian coordinate (Imamura et al., 2006) as

$$
\frac{\partial \eta}{\partial t}+\frac{\partial M}{\partial x}+\frac{\partial N}{\partial y}=0
$$

$$
\begin{aligned}
& \frac{\partial M}{\partial t}+\frac{\partial}{\partial x}\left(\frac{M^{2}}{D}\right)+\frac{\partial}{\partial y}\left(\frac{M N}{D}\right)+g D \frac{\partial \eta}{\partial x}+\frac{\tau_{x}}{\rho}=0 \\
& \frac{\partial N}{\partial t}+\frac{\partial}{\partial x}\left(\frac{M N}{D}\right)+\frac{\partial}{\partial y}\left(\frac{N^{2}}{D}\right)+g D \frac{\partial \eta}{\partial y}+\frac{\tau_{y}}{\rho}=0
\end{aligned}
$$




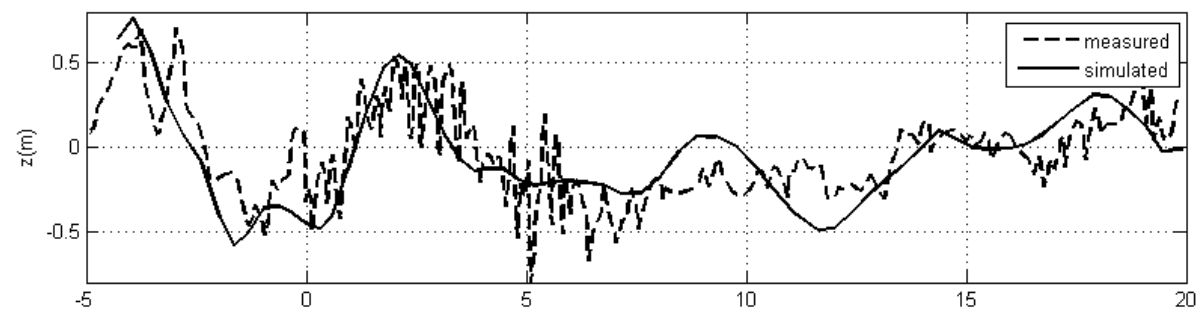

Fig. 2. Surface elevation for North Sumatra (December 2004) tsunami: computations vs. satellite data (Jason-1 path).

Table 1. Values of Manning's roughness for certain types of sea bottom (Imamura et al., 2006).

\begin{tabular}{llll}
\hline Channel Material & $n$ & Channel Material & $n$ \\
\hline Neat cement, smooth metal & 0.010 & Natural channels in good condition & 0.025 \\
Rubble masonry & 0.017 & Natural channels with stones and weeds & 0.035 \\
Smooth earth & 0.018 & Very poor natural channels & 0.060 \\
\hline
\end{tabular}

Here $D=h+\eta$ is the total water depth, where $h$ is the still water depth and $\eta$ is the sea surface elevation. $M$ and $N$ are the water velocity fluxes in the $\mathrm{x}$ - and $\mathrm{y}$-directions, respectively,

$M=\int_{-h}^{\eta} u d z=u(h+\eta)=u D$

$N=\int_{-h}^{\eta} v d z=v(h+\eta)=v D$

Terms $\tau_{x}$ and $\tau_{y}$ are due to the bottom friction in the $\mathrm{x}$ - and $\mathrm{y}$-directions, respectively, which is function of friction coefficient $f$. The friction coefficient can be computed from Manning's roughness $n$ by the following relationship

$n=\sqrt{\frac{f D^{1 / 3}}{2 g}}$

Manning's roughness is usually chosen as a constant for a given condition of sea bottom (see Table 1). For future analysis it is important to note that $f$ increases when the total water depth $D$ decreases. The bottom friction terms are expressed by

$$
\begin{aligned}
& \frac{\tau_{x}}{\rho}=\frac{n^{2}}{D^{7 / 3}} M \sqrt{M^{2}+N^{2}} \\
& \frac{\tau_{y}}{\rho}=\frac{n^{2}}{D^{7 / 3}} N \sqrt{M^{2}+N^{2}}
\end{aligned}
$$

The above expression shows that the bottom friction increases with the fluxes, and inversely proportional to the depth. Thus wave energy dissipates faster when it propagates in shallow water areas.

\subsection{Code modifications and improvements}

Modern tsunami research experiences two contradictory trends, one is to include more physical phenomena (previously neglected) into consideration, and another is to speed up the code to be used for the operational tsunami forecast. The optimal code for tsunami modeling supposed to be sufficiently accurate and fast; however, the notion of accuracy and speed is changing with time to reflect growing computational power and better understanding of tsunami physics.

The original TUNAMI-N2 model neglects Earth's curvature and Coriolis force. To capture these effects the NSWE model is reformulated as in spherical coordinates. The model is also modified to take into account dispersion terms. The equations are rewritten as

$$
\begin{gathered}
\frac{\partial \eta}{\partial t}+\frac{1}{R \cos \phi}\left[\frac{\partial M}{\partial \lambda}+\frac{\partial(N \cos \phi)}{\partial \phi}\right]=0 \\
\frac{\partial M}{\partial t}+\frac{1}{R \cos \phi} \frac{\partial}{\partial \lambda}\left(\frac{M^{2}}{D}\right)+\frac{1}{R} \frac{\partial}{\partial \phi}\left(\frac{M N}{D}\right) \\
+\frac{g D}{R \cos \phi} \frac{\partial \eta}{\partial \lambda}+\frac{\tau_{x}}{\rho}=(2 \omega \sin \phi) N \\
+\frac{g D}{R \cos \phi} \frac{\partial h}{\partial \lambda}+\frac{1}{R \cos \phi} \frac{\partial D \psi}{\partial \lambda}
\end{gathered}
$$

$$
\begin{gathered}
\frac{\partial N}{\partial t}+\frac{1}{R \cos \phi} \frac{\partial}{\partial \lambda}\left(\frac{M N}{D}\right)+\frac{1}{R} \frac{\partial}{\partial \phi}\left(\frac{N^{2}}{D}\right)+\frac{g D}{R} \frac{\partial \eta}{\partial \phi} \\
+\frac{\tau_{y}}{\rho}=-(2 \omega \sin \phi) M+\frac{g D}{R} \frac{\partial h}{\partial \phi}+\frac{1}{R} \frac{\partial D \psi}{\partial \phi}
\end{gathered}
$$

where $\lambda$ is longitude and $\phi$ is latitude. The radius and angular velocity of the Earth are given by $R=6378.137 \mathrm{~km}$ and 

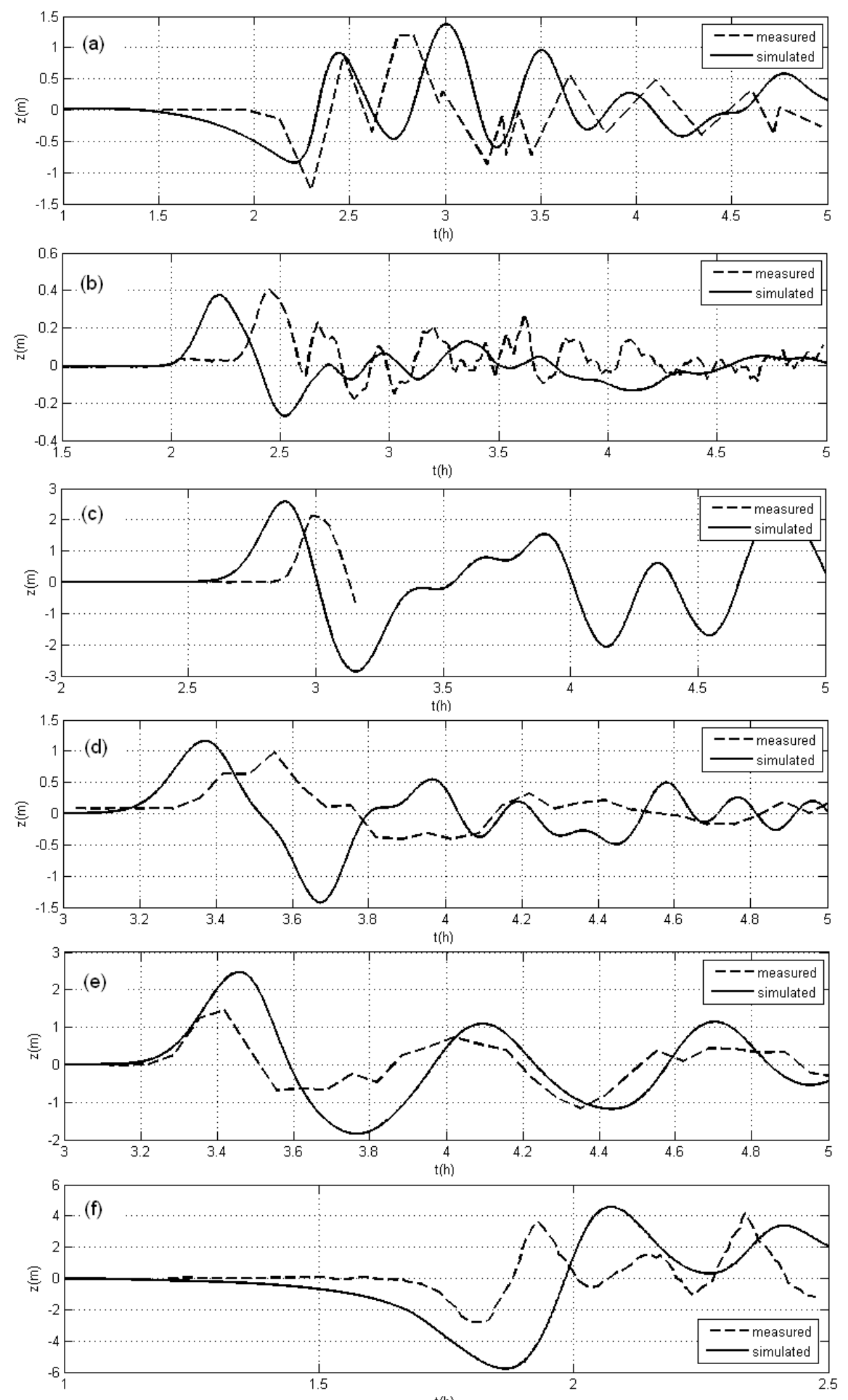

t(h)

Fig. 3. Surface elevation for North Sumatra (December 2004) tsunami: computations vs. measurements at (a) Taphaonoi, (b) Cocos Island, (c) Columbo, (d) Gan, (e) Male, (f) Mercator yacht. 

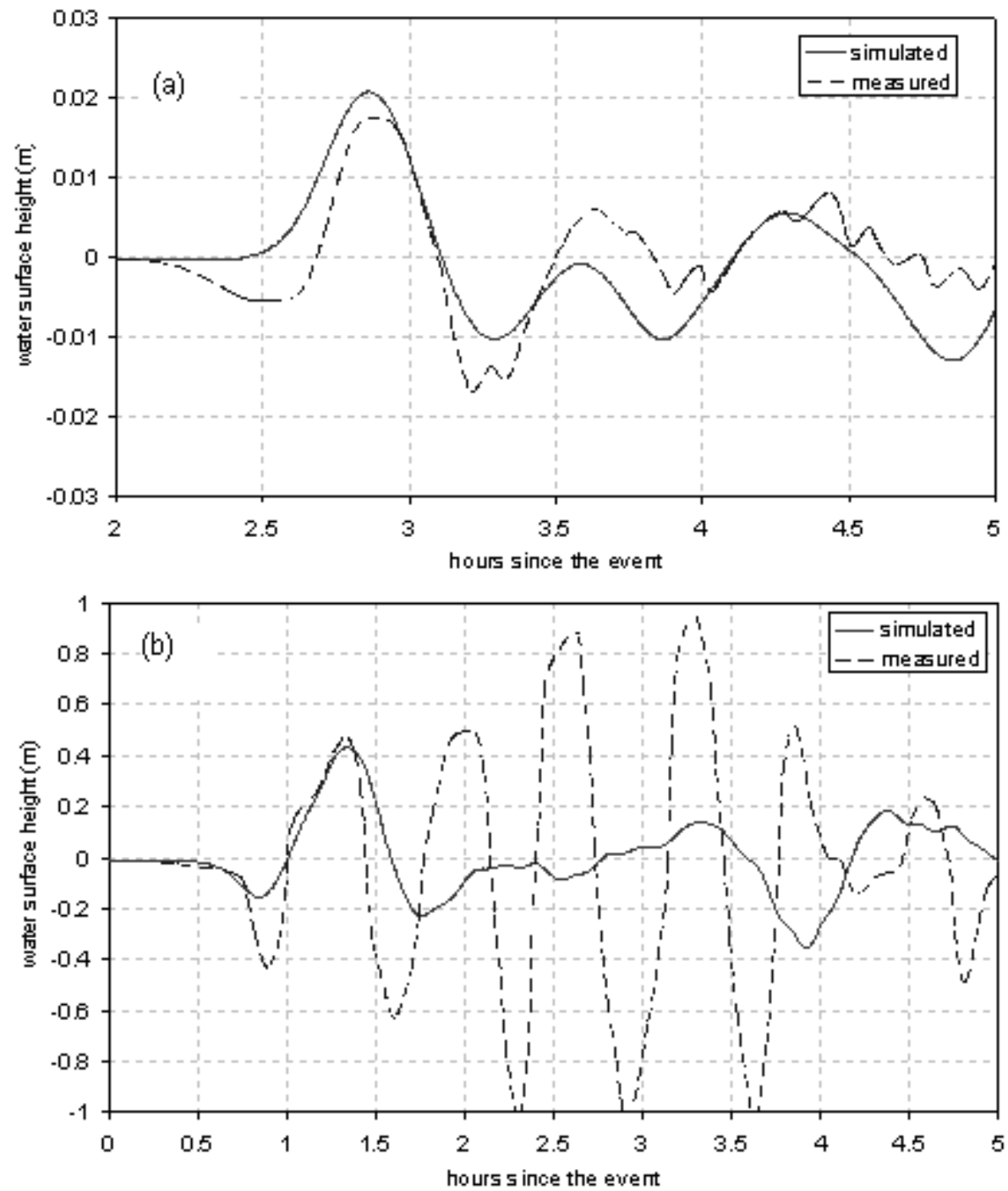

Fig. 4. Surface elevation for South Sumatra (12 September 2007) tsunami: computations vs. measurements at (a) Thai buoy "23401", (b) Padang tide gage.

$\omega=7.27 \times 10^{-5} \mathrm{rad} / \mathrm{s}$, respectively. The dispersion potential function is defined as (Horrillo et al., 2006)

$\psi=\frac{h^{2}}{3}\left(\frac{1}{R \cos \phi} \frac{\partial^{2} u}{\partial \lambda \partial t}+\frac{1}{R} \frac{\partial^{2} v}{\partial \phi \partial t}\right)$

Neglecting the nonlinear terms and substituting the potential function into the governing equation, we obtains the Poisson equation

$$
\begin{aligned}
& \frac{h^{2}}{3}\left(\frac{1}{R^{2} \cos ^{2} \phi} \frac{\partial^{2} \psi}{\partial \lambda^{2}}+\frac{1}{R^{2}} \frac{\partial^{2} \psi}{\partial \phi^{2}}\right)-\psi \\
& =\frac{g h^{2}}{3}\left(\frac{1}{R^{2} \cos ^{2} \phi} \frac{\partial^{2} \eta}{\partial \lambda^{2}}+\frac{1}{R^{2}} \frac{\partial^{2} \eta}{\partial \phi^{2}}\right)
\end{aligned}
$$

At every time-step, the solution of the Poisson equation gives the dispersion potential, then the Boussinesq equation is solved to get the wave field.

As indicated by Horrillo et al. (2006), solution of this set of Boussinesq and Poisson equations with an explicit numerical scheme requires a careful choice of spatial and temporal resolutions due to more stringent stability conditions imposed by dispersive terms. To achieve the stability, much smaller time-step is needed, and the spatial resolution has to satisfy the condition of $d x \geq 1.5 \mathrm{~h}$. With the typical ocean depth of $4 \mathrm{~km}$, the spatial discretization must be greater than $6 \mathrm{~km}$. This resolution is too poor to represent fine coastal lines and islands. Thus in this application, a modified-explicit centraldifference scheme is applied to solve the Boussinesq and Poisson equations. In this scheme, the current velocity term is explicitly computed from previous time-step, while the 


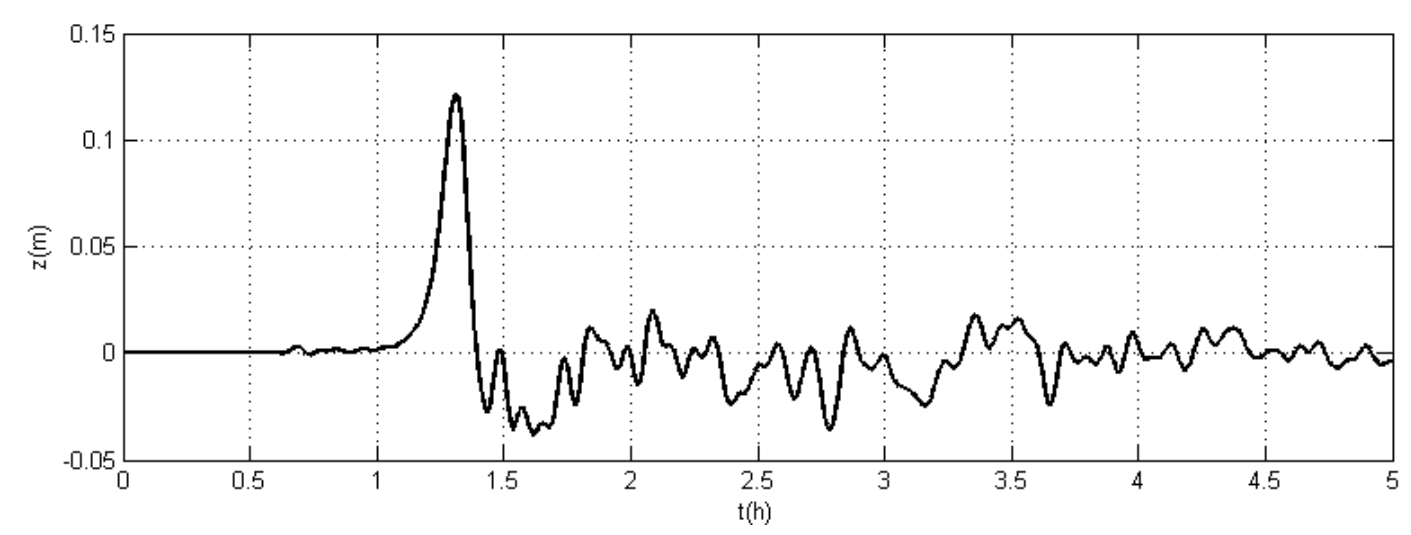

Fig. 5. Simulated sea surface elevation at Cocos Island for South Sumatra (12 September 2007) tsunami. Measurements reported: wave amplitude $0.11 \mathrm{~m}$, arrival time $1.42 \mathrm{~h}$, wave period $0.37 \mathrm{~h}$.
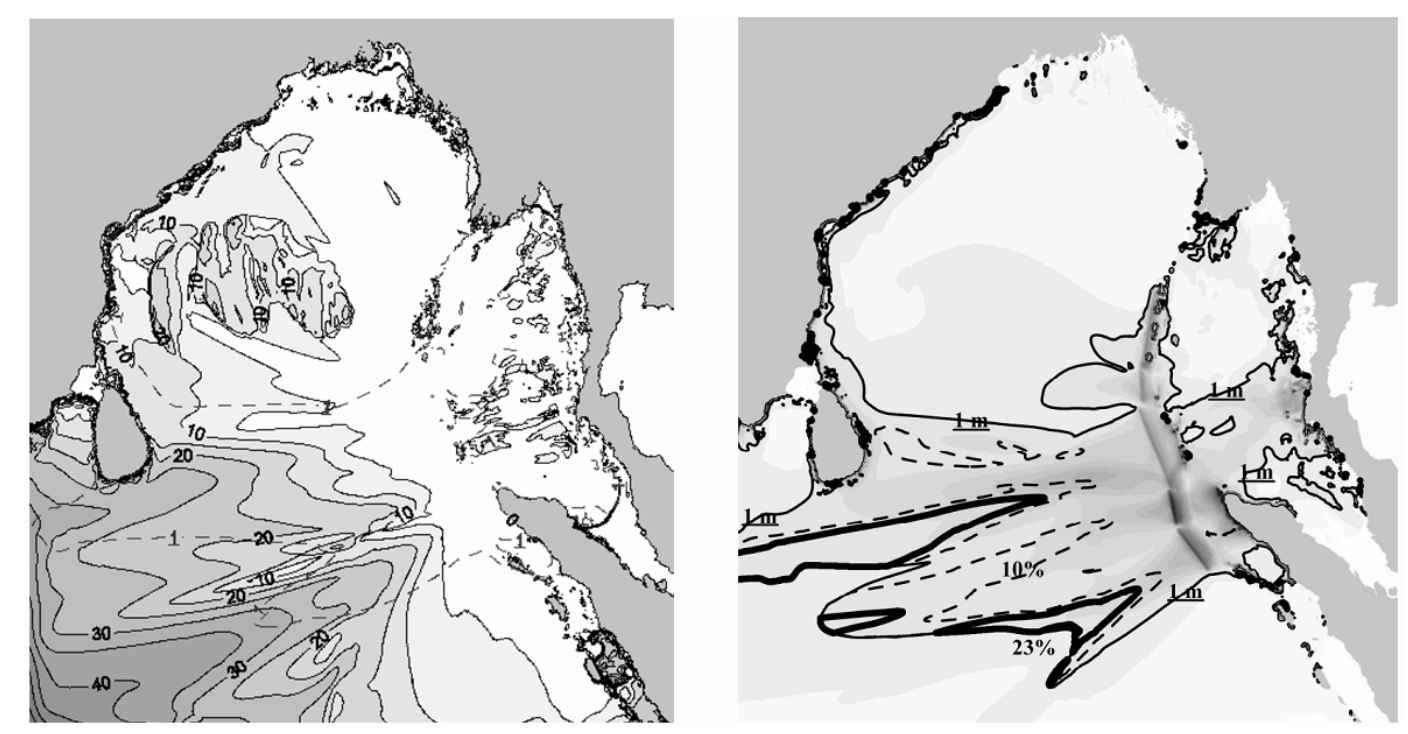

Fig. 6. Percentage difference in maximum tsunami height computed using Boussinesq and NSWE models (left - modified TUNAMI-N2, right - FUNWAVE, Grilli et al., 2006, the same set of fault parameters are used). Dot line in the left figure is contour of $1 \mathrm{~m}$ wave height.

elevation term is time-centred (averaged between two time steps). Boundary condition for the Poisson equation is obtained via evaluation of potential function at the boundaries. To maintain stability of the solution algorithm, the time-step had to be reduced by $30 \%$, resulting in total computational time increase by about $30 \%$ as compare to the code without dispersion term.

Using the memory accessing feature recommended in FORTRAN, all the loops in the program are optimized. The modified TUNAMI-N2 is estimated 3-4 times faster than the original code.

For easier references, in the text from here on the modified version of TUNAMI-N2 is called TUNAMI-N2-NUS, while TUNAMI-N2 is referred to the original version.

\subsection{Initial and boundary conditions}

The initial condition of TUNAMI-N2 is often prescribed as a static elevation of sea level due to the fault displacement (rupture) at the bottom. For the sub-sea earthquake, the rupture typically has duration of minutes, which can be considered as instantaneous comparing to the time-scale of tsunami propagation. The hydrodynamic effect is often neglected since the horizontal size of the wave profile is sufficiently larger than the water depth at the source. Thus, the initial surface wave is assumed to be identical to the vertical static coseismic displacement of the sea floor which is given by Masinha and Smylie (1971) for inclined strike-slip and dip-slip faults. Similar algorithm can be obtained from Okada (1985).

Initial sea surface deformation due to multiple and nonsimultaneous ruptures can be calculated in the TUNAMI-N2- 

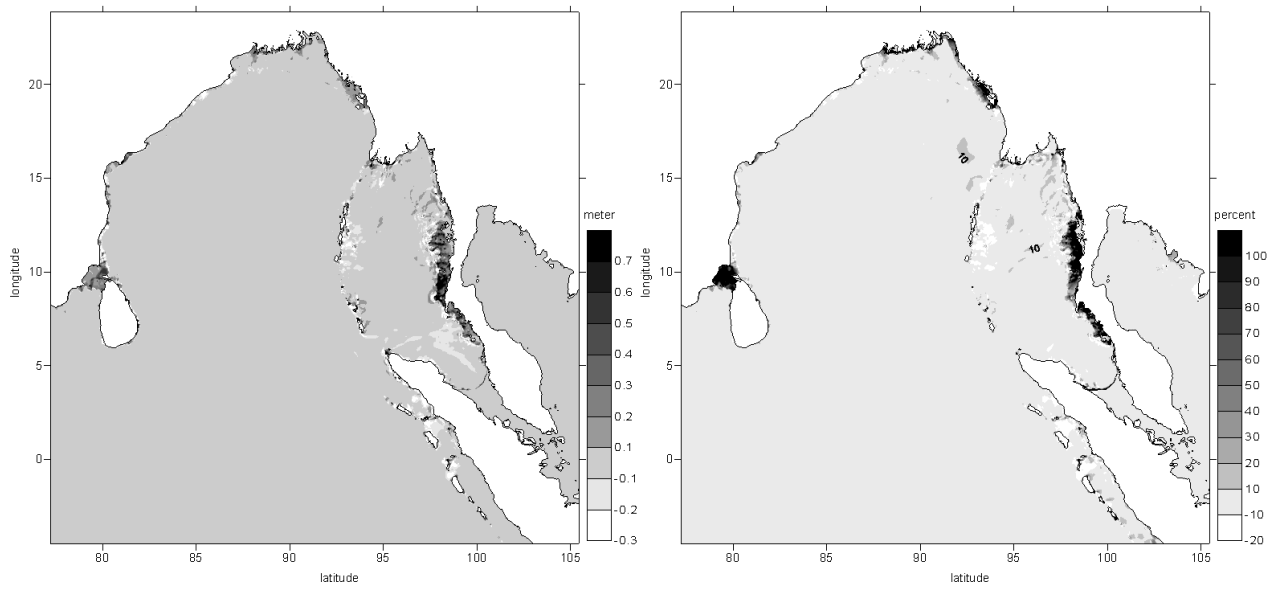

Fig. 7. Model sensitivity to astronomic tide. Differences in maximum tsunami amplitude for high and low water level (left: absolute values, right: percentage difference).
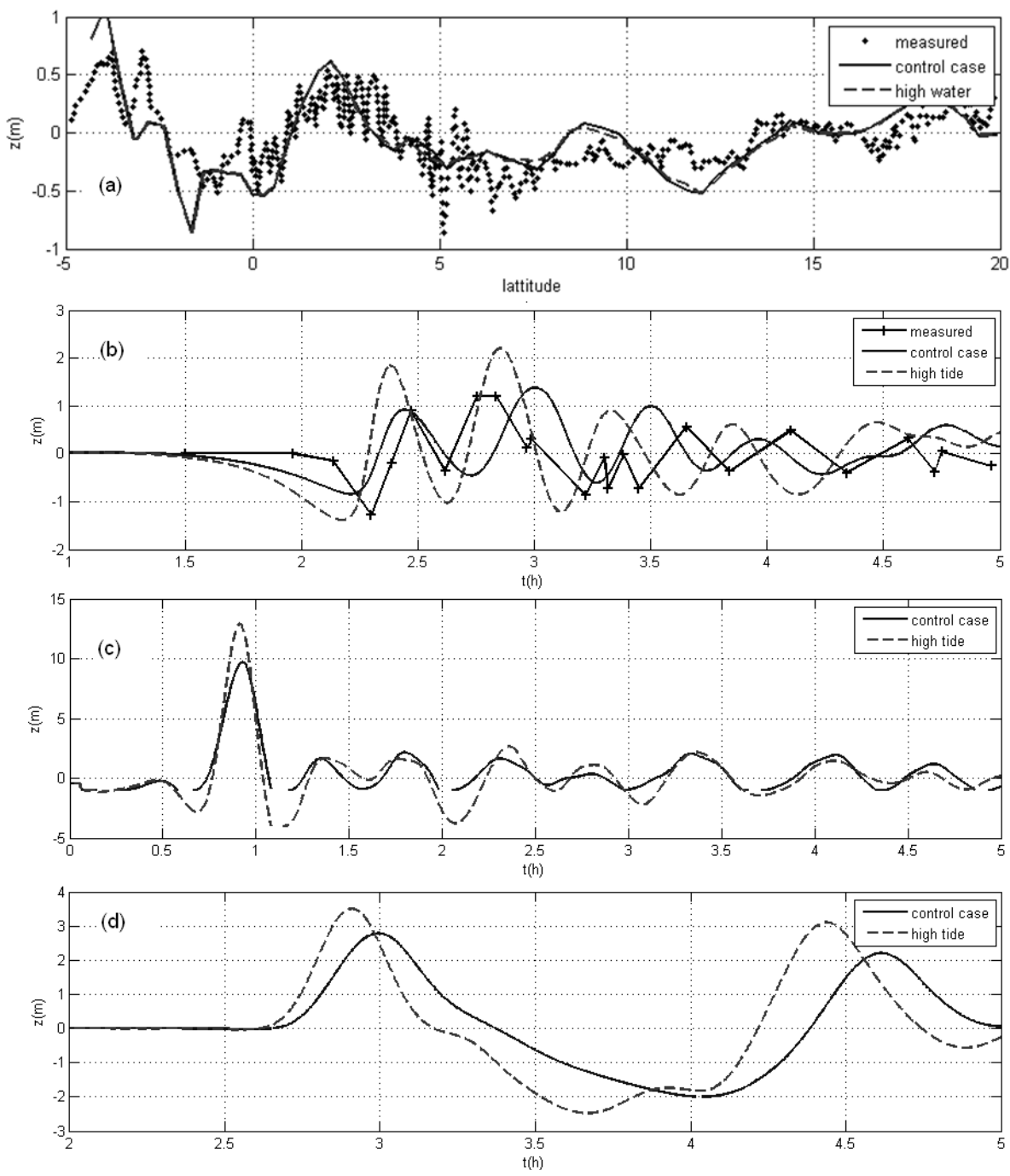

Fig. 8. Model sensitivity to astronomic tides. Surface elevation at: (a) Jason-1 path; (b) Taphaonoi (98.442, 7.801); (c) Aceh (95.309, 5.568); (d) Pulikat $(80.333,13.383)$. 

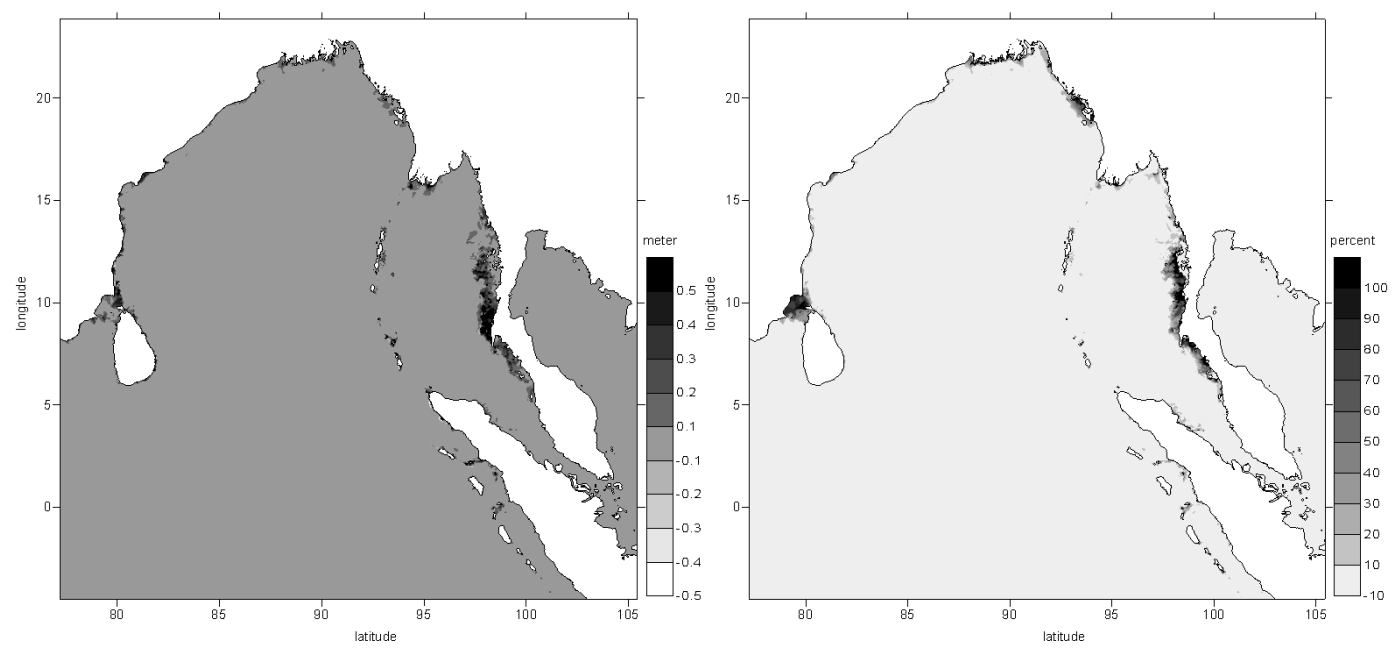

Fig. 9. Differences in maximum tsunami amplitude computed for Manning coefficients $n=0.015$ and $n=0.025$ (control case). Left - absolute values, right - percentage difference.

Table 2. The fault parameters for the Northern Sumatra earthquake 26 December 2004.

\begin{tabular}{llllll}
\hline Segment \# & 1 & 2 & 3 & 4 & 5 \\
\hline Time of occurrence $(\mathrm{s})$ & 0 & 212 & 528 & 873 & 1213 \\
Epicenter Lon $\left({ }^{\circ} \mathrm{E}\right)$ & 94.57 & 93.9 & 93.21 & 92.6 & 92.87 \\
Epicenter Lat $\left({ }^{\circ} \mathrm{N}\right)$ & 3.8 & 5.2 & 7.41 & 9.7 & 11.7 \\
Fault length $(\mathrm{km})$ & 210 & 150 & 390 & 150 & 350 \\
Fault width $(\mathrm{km})$ & 120 & 120 & 120 & 95 & 95 \\
Strike angle $\left({ }^{\circ}\right)$ & 323 & 348 & 338 & 356 & 10 \\
Dip angle $\left({ }^{\circ}\right)$ & 12 & 12 & 12 & 12 & 12 \\
Slip angle $\left({ }^{\circ}\right)$ & 90 & 90 & 90 & 90 & 90 \\
Displacement $(\mathrm{m})$ & 35 & 25 & 20 & 12 & 12 \\
Focal depth $(\mathrm{km})$ & 25 & 25 & 25 & 25 & 25 \\
\hline
\end{tabular}

NUS. The fault model of Masinha and Smylie (1971) is repeated for each individual rupture and the resulting surface deformation is linearly added to the current sea surface.

Moving boundary condition is applied for land boundaries to allow for run-up calculation, and free transmitted wave is applied at the open boundaries.

\subsection{Verification of the TUNAMI-N2-NUS model}

The TUNAMI-N2-NUS model is rigorously tested and verified using different test cases, including hindcast of the North Sumatra event (26 December 2004) and other recent tsunamis: Taiwan (26 December 2006), Solomon Island (2 April 2007). During the event of $8.4 \mathrm{Mw}$ earthquake off Bengkulu, South Sumatra (12 September 2007), the model was used in a forecast mode and provided results about $2 \mathrm{~h}$ after the earthquake. In this paper, we present the comparisons of the TUNAMI-N2-NUS model to water elevation data recorded during the North Sumatra and South Sumatra events. Bathymetry and topography for these simulations were taken from the NGDC digital databases on a 2-min latitude/longitude grid (Etopo2, NGDC/NOAA).

For North Sumatra event five fault segments were assumed to rupture sequentially from south to north (Fig. 1, Table 2). Comparison to Jason-1 satellite data and some tide gages around Indian Ocean coasts are given in Figs. 2 and 3. Figure 2 shows that simulated data follow very well the satellite data. First wave amplitude of $0.6 \mathrm{~m}$ can be hidcasted, but the second observed peak is missing in computations. At the tide gages and the yacht (Fig. 3), amplitude of the first wave is reproduced well accept at Male (Maldives). Particularly good agreement is observed at Taphaonoi. However, time lags of 6-10 min are observed at other station. Similar time lags were shown in the comparison of FUNWAVE's result and measurement in Grilli et al. (2007).

Figures 4 and 5 show comparison of TUNAMI-N2-NUS computations with measurements of tsunami generated by earthquake offshore of Bengkulu, South Sumatra. Fault parameters for this event are given in Table 3. Comparison with Thai buoy in deep ocean shows good model performance in terms of arrival time of the first wave, amplitude and wave period. Computation at Padang compares very well for the first wave but fails to reproduce the subsequent waves. The oscillation pattern looks like a resonance wave at the semienclosed domain formed by Sumatra coast and Mentawai Islands. To obtain similar results in the model one would require better bathymetry and topography resolution in the area. Computations at Cocos Island (Fig. 5) show that the first tsunami peak arrives $1.32 \mathrm{~h}$ after the earthquake with the amplitude $0.12 \mathrm{~m}$ and the period is $0.39 \mathrm{~h}$. These agree well with the data reported in tsunami bulletin number 005 of PTWC/NOAA/NWS issued at 15:05 UTC 12 September 2007 (wave amplitude $0.11 \mathrm{~m}$, arrival time $1.42 \mathrm{~h}$, wave pe$\operatorname{riod} 0.37 \mathrm{~h})$. 
Table 3. The fault parameters for the Southern Sumatra earthquake (12 September 2007).

\begin{tabular}{llllll}
\hline Epicenter Lon $\left({ }^{\circ} \mathrm{E}\right)$ & 101.4 & Fault width $(\mathrm{km})$ & 120 & Slip angle $\left({ }^{\circ}\right)$ & 70 \\
\hline Epicenter Lat $\left({ }^{\circ} \mathrm{S}\right)$ & 4.51 & Strike angle $\left({ }^{\circ}\right)$ & 323 & Displacement $(\mathrm{m})$ & 5 \\
Fault length $(\mathrm{km})$ & 186.6 & Dip angle $\left({ }^{\circ}\right)$ & 8 & Focal depth $(\mathrm{km})$ & 30
\end{tabular}
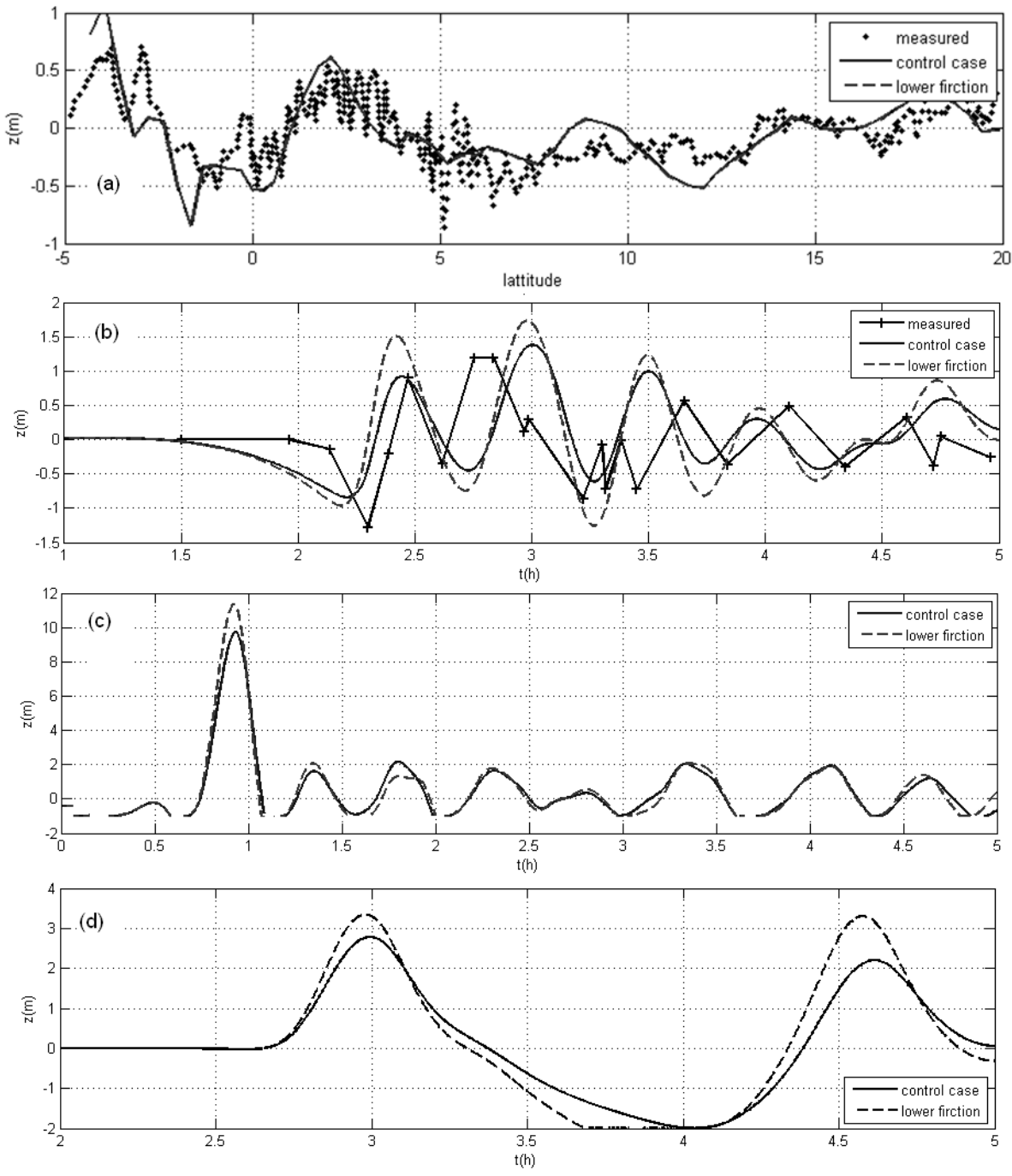

Fig. 10. Model sensitivity to friction coefficient. Surface elevation at: (a) Jason-1 path; (b) Taphaonoi (98.442, 7.801); (c) Aceh (95.309, 5.568); (d) Pulikat (80.333, 13.383).

Another verification session depicts performance of linear dispersive model mode versus fully nonlinear dispersive case for TUNAMI-N2-NUS and FUNWAVE (Grilli et al., 2006). Comparison made in Fig. 6 shows a good agreement between the two models.

\section{Tsunami propagation sensitivity study}

As computational power increases and more accurate numerical and physical approaches become available, one has to re-evaluate currently used operational codes to ensure that the most important and yet computationally affordable phenomena are taken into account. Model sensitivity to variation of the newly included parameters is an important part of the testing cycle. The TUNAMI-N2-NUS model is computationally explored to evaluate effects of tide, bottom friction, Coriolis force, spherical coordinates and dispersion on tsunami propagation. The non-dispersive version of TUNAMI-N2-NUS (without dispersion term) serves as control model (NSWE in spherical coordinates with Coriolis force and nonlinear friction). 

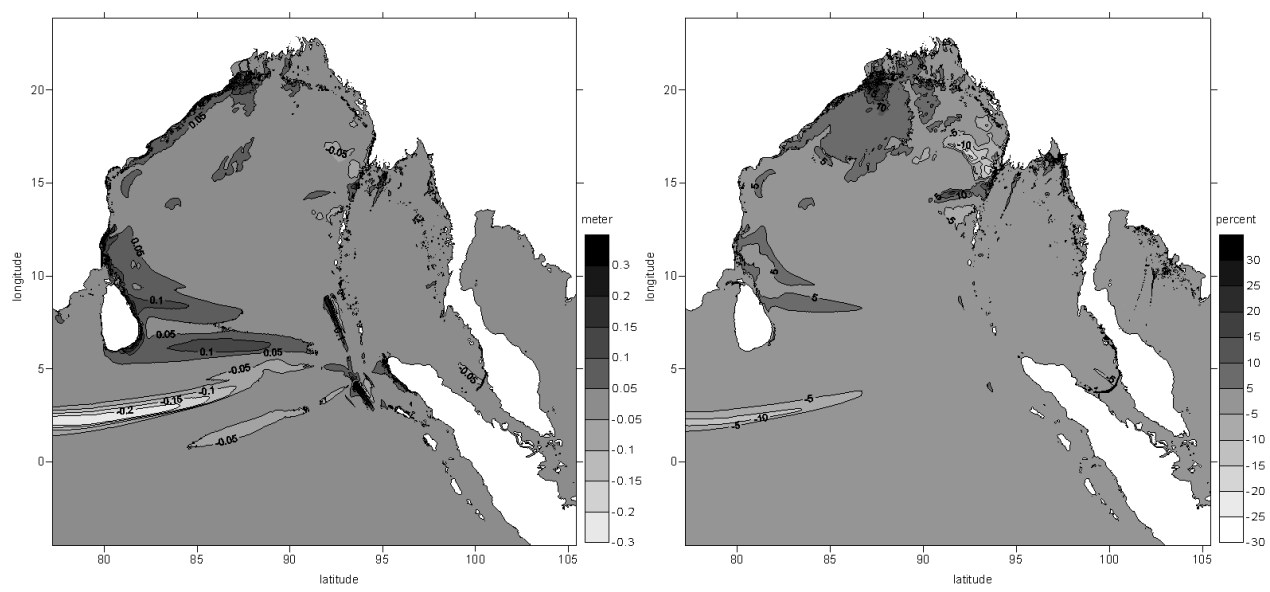

Fig. 11. Model sensitivity to Cartesian and spherical coordinates. Differences in maximum tsunami amplitude (left - absolute values, right - percentage difference).
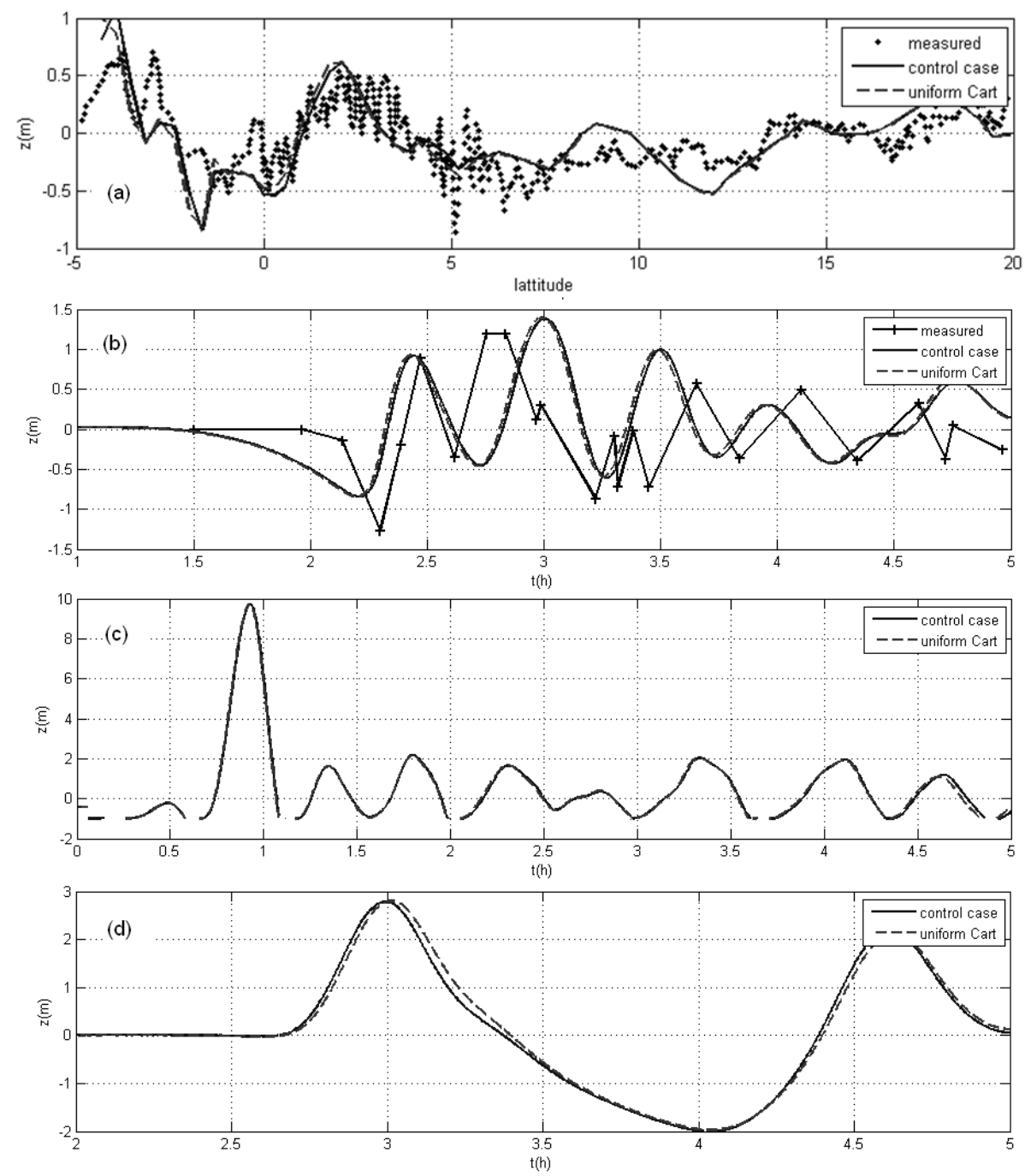

Fig. 12. Model sensitivity to uniform Cartesian ("Cart") and spherical coordinates ("control case"). Surface elevation at: (a) Jason-1 path; (b) Taphaonoi; (c) Aceh; (d) Pulikat. 

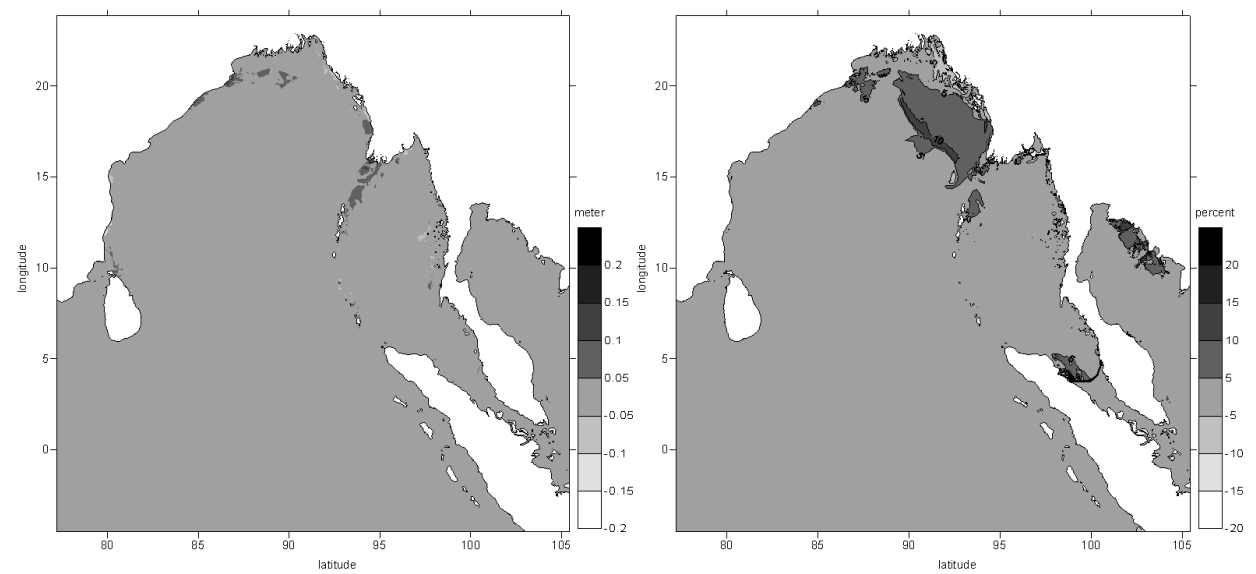

Fig. 13. Differences in maximum tsunami amplitude computed without and with Coriolis terms (left - absolute values, right - percentage difference).
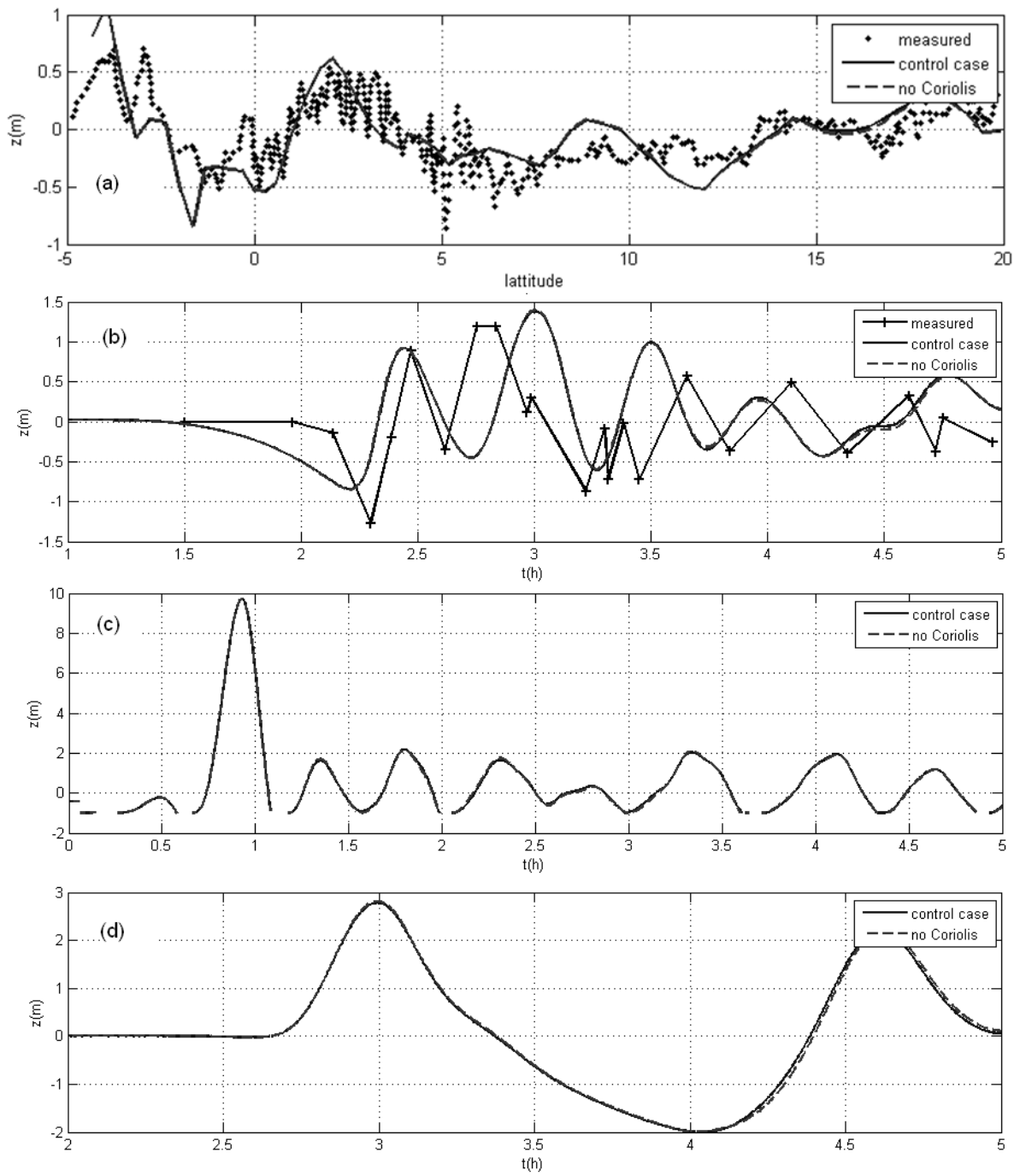

Fig. 14. Tsunami propagation sensitivity to Coriolis force at: (a) Jason-1 path; (b) Taphaonoi (98.442, 7.801); (c) Aceh (95.309, 5.568); (d) Pulikat $(80.333,13.383)$. 

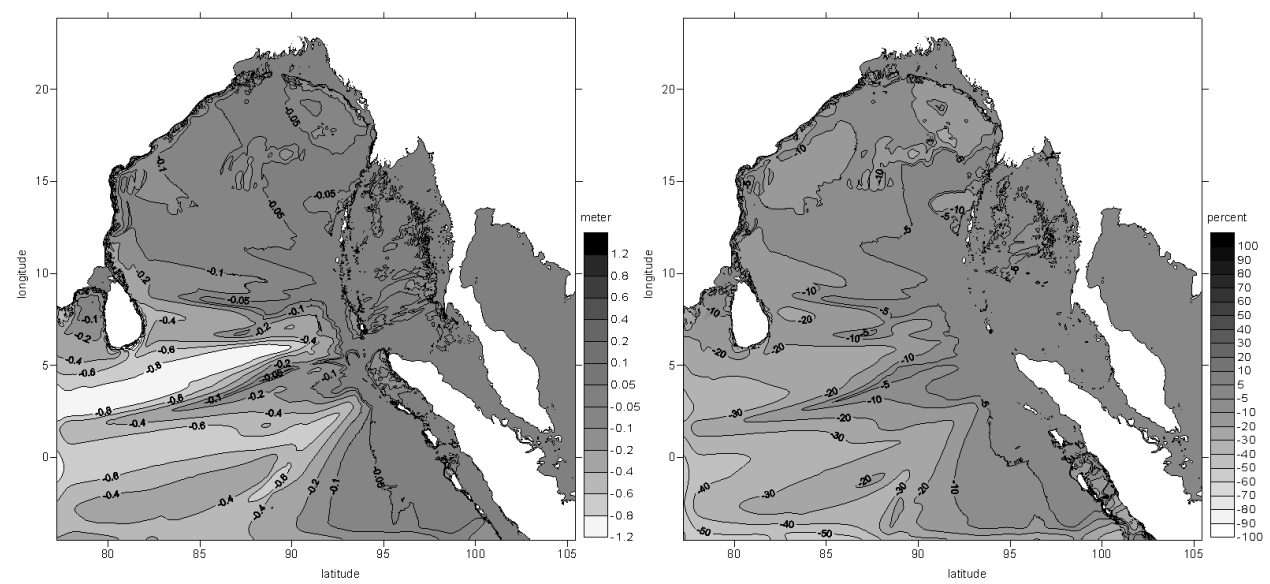

Fig. 15. Differences in maximum tsunami amplitude computed with and without dispersion terms (left - absolute values, right - percentage difference).
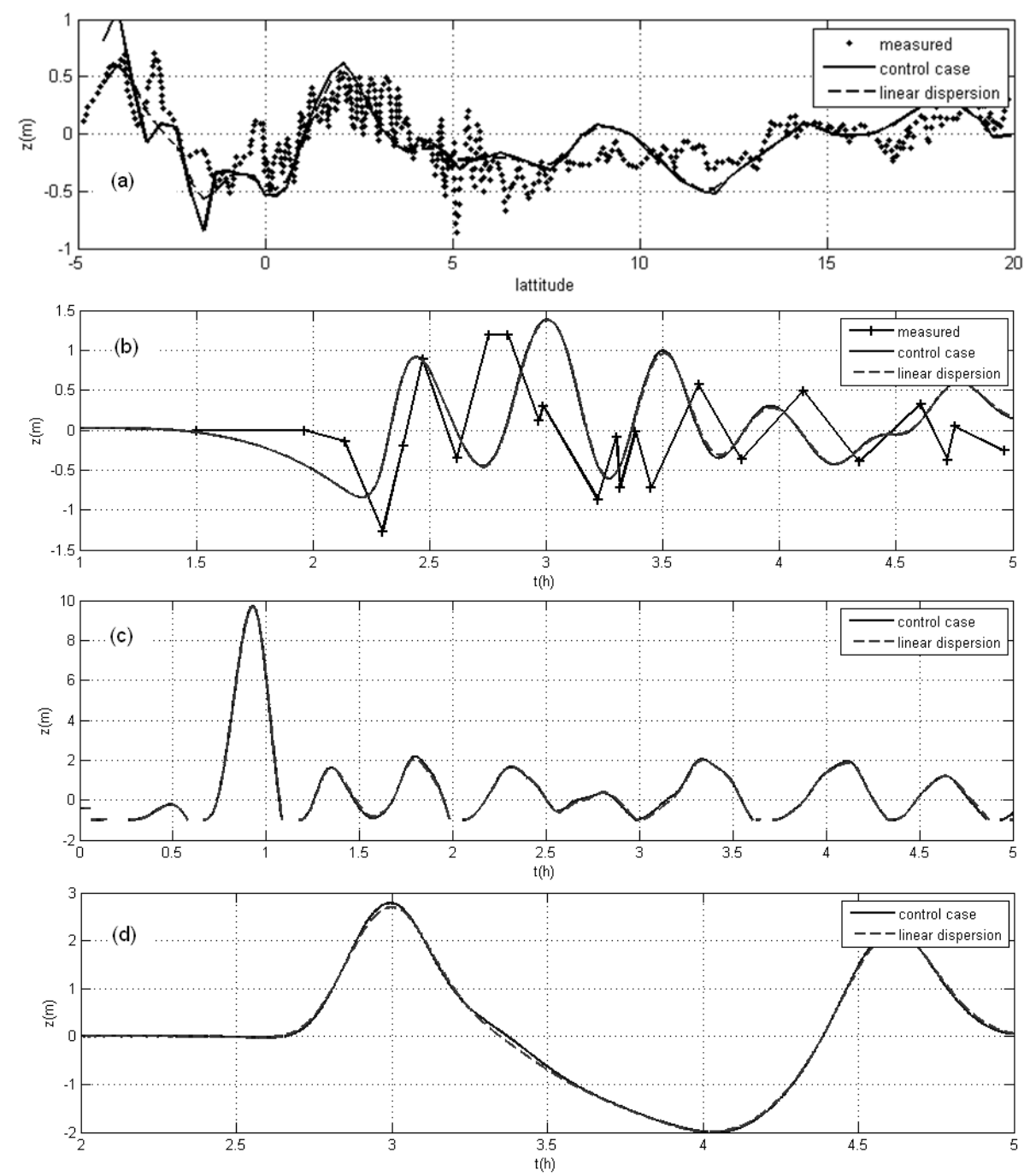

Fig. 16. Model sensitivity to dispersion term at: (a) Jason-1 path; (b) Taphaonoi $(98.442,7.801)$; (c) Aceh $(95.309,5.568)$; (d) Pulikat $(80.333,13.383)$. 
In this study, the TUNAMI-N2-NUS model is applied to simulate tsunami caused by the Northern Sumatra (December 2004) earthquake. Utilized computational domain and bathymetry are shown in Fig. 1. The domain is discretized with rectangular grid having $848 \times 852$ nodes and 2 min $(\sim 3.7 \mathrm{~km})$ resolution. Bathymetry is taken from the NGDC digital databases of seafloor and land elevations on a 2-min latitude/longitude grid (Etopo2, NGDC/NOAA). The earthquake fault parameters are given in Table 2. There were identified 5 fault segments occurred sequentially as the rupture propagates from south to north (Fig. 1).

\subsection{Effect of tide}

A typical tsunami wave is much shorter than astronomically driven tidal waves. Therefore, the tidal range was usually neglected during tsunami modeling, and the computed sea level dynamics is superimposed with the tidal one after the computations. However, in shallow areas with strong tidal activity, dynamic nonlinear interaction of tidal and tsunami waves can amplify the magnitude of inundation. To study this effect, water level change due to tide need to be included in the governing equations (Kowalik et al., 2006; Myers and Baptista, 2001).

Additionally to the dynamic nonlinear interaction localized in inundation zones, there is a potential for a tide to change parameters of propagating tsunamis due to a simple static change of water depth by a few meters (tidal range). This effect might be important considering that a large area of the ocean may experience simultaneous elevation or subsidence due to the tide. For example, in the area of Thailand and Malaysia coasts, the tidal range varies roughly between $-1.5 \mathrm{~m}$ and $1.5 \mathrm{~m}$ relative to the mean sea level. Thus we compare two scenarios of tsunami propagation, one occurred during low tide and another at high tide level which is $3 \mathrm{~m}$ difference in water depth (Figs. 7 and 8). Figure 7 shows the differences in maximum tsunami amplitude between the higher and lower water depth. It can be seen that there is an extra increase of water level up to $0.7 \mathrm{~m}$ (or $100 \%$ wave amplitude) nearshore. Large differences present at coasts of Thailand, Malaysia, Bangladesh and west of Sri Lanka which have large area of shallow water shelf. Comparisons of tsunami height changes at deep water and tide gages are shown in Fig. 8. There is no clear difference observed along the Jason-1 path due to the water being too deep. However, tsunami height can double at shallower water, such as Taphaonoi. Significant differences also present at Aceh and Pulikat. Computations show that not only the tsunami height, but arrival time could be affected by astronomical tide. One can see in Figure 8b,d that the first peak arrives $\sim 10$ min earlier in the computation with higher water level. Many researchers attributed discrepancy of tsunami computations in the near-shore zones to the bathymetry inaccuracies, but a similar error scale could be obtained by neglecting astronomical tides. These estimations, especially more correct compu- tation of arrival time, could be important for better evacuation planning.

\subsection{Effect of sea bottom friction}

Bottom friction phenomenon could be important in shallow waters, such as south part of Malacca Strait where depth is less than $50 \mathrm{~m}$. This effect is parameterized in the model using Manning coefficient varied with the bottom roughness. To investigate model sensitivity to variation of bottom roughness, Manning's coefficient was chosen as 0.025 and 0.015 (see Table 1 for the entire range of values). The differences of computed maximum tsunami amplitude between the two scenarios are plotted in Figs. 9 and 10, indicating that tsunami height at the lower friction can increase by $0.5 \mathrm{~m}$ nearshore of Malaysia, Thailand and SriLanka, however the arrival time is not affected. The friction is important only in shallow water, whereas in the deep ocean the effect is negligible.

\subsection{Effect of Coriolis force and spherical coordinates}

Figures 11 and 12 show the model sensitivity to application of Cartesian and spherical coordinates, while Figs. 13 and 14 compare simulations with and without the Coriolis terms.

Usage of spherical coordinates may lead to a $0.3 \mathrm{~m}$ (or $\sim 30 \%$ ) difference of computed maximum tsunami amplitude (Fig. 11). Although the effect of curvature is small compared to other phenomena, it is increasing at higher latitude (northeast coast of India) or farther from the source in the main direction of the tsunami propagation, such as coast of Sri Lanka. As shown in Fig. 12a, slightly change can be seen in the leading wave amplitude in deep ocean.

Governing equations indicate that Coriolis effect is expected to be larger at higher latitudes or for higher current fluxes. Figure 13 particularly depicts a small variation of maximum tsunami height $(10 \%-15 \%)$ at the northern coasts. There is no clear difference found in Fig. 14.

\subsection{Effect of dispersion}

Differences in maximum tsunami height between Boussinesq and NSWE approximations are presented in Figs. 15 and 16. The largest difference of maximum wave height is observed in the deep water in the main direction of tsunami wave train. Due to the frequency dispersion, longer and higher waves travel faster and separate from the shorter and smaller waves, leading to decrease of computed tsunami height. The dispersion effect is stronger in the direction of tsunami propagation and toward deep waters where the wave speed is the largest.

As shown in Fig. 15 dispersion effect causes a drop of 0.4$0.6 \mathrm{~m}(40 \%-60 \%)$ in computed maximum tsunami amplitude in the south-west area of the domain. A $20 \%$ reduction of wave amplitude is depicted at the coast of Sri Lanka. No clear change of wave height is observed at the east side of the source. It is clearly seen in Fig. 16a where simulated wave is compared to Jason-1 data. Significant drop in leading wave 
amplitude due to dispersion is shown. At other stations the codes with and without dispersion term produce almost the same result.

\section{Conclusions}

In this study, several modifications are implemented into the TUNAMI-N2 code to consider potentially important physical phenomena, such as astronomic tide, sea bottom friction, Coriolis, spherical coordinates and wave dispersion. The resulting code TUNAMI-N2-NUS is successfully tested against other models and measurements of real tsunami events. Sensitivity analysis shown that out of the considered phenomena (in order of significance), astronomic tide and bottom friction may have large impact to tsunami propagation in shallow waters, and thus need to be included in a research code considering wave-shore interactions. Dispersion can leads to a notable change in amplitude of tsunami propagating a large distance in deep water; therefore, it needs to be included in trans-ocean tsunami simulation. Time required to solve fully nonlinear dispersion model to gain a bit of accuracy locally, may defer the model usage for operational forecast, but still may be important for run-up simulation. Effects of Coriolis force and spherical coordinates are smaller compared to others, but still can be used for far field tsunami modeling within the same computational resources. The final decision on when and what phenomena have to be included lays in the domain of available computational resources and purpose of a particular study or code. Taking into account a number of uncertainties, in operational forecast one might do well with the lightest (and quickest) code, whereas a research code can afford all the considered terms.

Acknowledgements. This study is conducted in Tropical Marine Science Institute (TMSI), National University of Singapore with financial support of National Environmental Agency. Help of TMSI staff is highly appreciated.

Edited by: S. Tinti

\section{References}

Etopo2, NGDC/NOAA: Surface of the Earth 2-minute color relief images, www.ngdc.noaa.gov/mgg/image/2minrelief.html, 2006.

Goto, C. and Ogawa, Y.: Numerical Method of Tsunami Simulation with the Leap-Frog Scheme, Translated for the Time Project by Shuto, N., Disaster Control Research Center, Faculty of Engineering, Tohoku University in June 1992, 1982.

Goto, C., Ogawa, Y., Shuto, N., and Imamura, F.: Numerical method of tsunami simulation with the leap-frog scheme (IUGG/IOC Time Project), IOC Manual, UNESCO, No. 35, 1997.

Grilli, S. T., Ioualalen, M., Asavanant, J., Shi, F., Kirby, T. J., and Watts, P.: Source Constraints and Model Simulation of the December 26, 2004 Indian Ocean Tsunami, ASCE J. Waterways, Port, Ocean and Coastal Engineering, 133(6), 414-428, 2007.
Horrillo, J. and Kowalik, Z.: Wave dispersion study in the Indian ocean tsunami of December 26, 2004, Science of Tsunami Hazards, 25(1), p. 42, 2006.

Imamura, F. and Shuto, N.: Numerical simulation of the 1960 Chilean Tsunami, in: Proceedings of the Japan-China (Taipei) Joint Seminar on Natural Hazard Mitigation, Kyoto, Japan, 1989.

Imamura, F., Yalciner, A. C., and Ozyurt, G.: Tsunami modelling manual, Online manual, http://ioc3.unesco.org/ptws/21/ documents/TsuModelMan-v3-ImamuraYalcinerOzyurt_apr06. pdf, 2006.

Kirby, T. J., Wei, G., Chen, Q., Kennedy, B., and Dalrymple, A. R.: FUNWAVE 1.0 Fully nonlinear Boussinesq wave model Documentation and user's manual, Research report no. CACR-98-06, September 1998.

Kowalik, Z. and Murty, T. S.: On some future tsunamis in the Pacific Ocean, Natural Hazards, 1(4), 349-369, 1989.

Kowalik, Z. and Proshutinsky, T.: Tide-Tsunami Interactions, Science of Tsunami Hazards, Vol. 24, No. 4, p. 242, 2006.

Manshinha, L. and Smylie, D. E.: The displacement fields of inclined faults, B. Seismol. Soc. Am., 61(5), 1433-1440, 1971.

Okada, Y.: Surface deformation due to shear and tensile faults in a half-space, B. Seismol. Soc. Am., 75, 1135-1154, 1985.

Shuto, N. and Goto, C.: Numerical simulations of the transoceanic propagation of Tsunamis, in: Sixth Congress Asian and Pacific Regional Division, International Association for Hydraulic Research, Kyoto, Japan, 1988.

Shuto, N., Goto, C., and Imamura, F.: Numerical simulation as a means of warning for near-field Tsunami, Coastal Engineering in Japan, 33(2), 173-193, 1990.

Shuto, N.: Numerical Simulation of Tsunamis - Its present and Near Future, Natural Hazards, 4, 171-191, 1991.

Tinti, S., Armigliato, A., Manucci, A., Pagnoni, G., Zaniboni, F., Yalciner, A. C., and Altinok, Y.: The Generating Mechanisms Of The August 17, 1999 Izmit Bay (Turkey) Tsunami: Regional (Tectonic) And Local (Mass Instabilities) Causes, Mar. Geol., 225(1-4), 311-330, 2006.

Weisz, R. and Winter, C.: Tsunami, tides and run-up: a numerical study, in: Proceedings of the International Tsunami Symposium, edited by: Papadopoulos, G. A. and Satake, K., Chania, Greece, 27-29 June 2005, 322, 2005.

Yalciner, A. C., Altinok, Y., and Synolakis, C. E.: Tsunami Waves in Izmit Bay After the Kocaeli Earthquake, Chapter 13, Kocaeli Earthquake, Earthquake Engineering Research Inst., USA, 2000.

Yalciner, A. C., Synolakis, A. C., Alpar, B., Borrero, J., Altinok, Y., Imamura, F., Tinti, S., Ersoy, S., Kuran, U., Pamukcu, S., and Kanoglu, U.: Field Surveys and Modeling 1999 Izmit Tsunami, in: International Tsunami Symposium ITS 2001, Session 4, Paper 4-6, Seattle, 7-9 August 2001, 557-563, 2001.

Yalciner, A. C., Alpar, B., Altinok, Y., Ozbay, I., and Imamura, F.: Tsunamis in the Sea of Marmara: historical documents for the past, models for future, Mar. Geol. (Special Issue), 190, 445463, 2002.

Yalciner, A., Pelinovsky, E., Talipova, T., Kurkin, A., Kozelkov, A., and Zaitsev, A.: Tsunamis in the Black Sea: Comparison of the historical, instrumental, and numerical data, J. Geophys. Res., 109, C12023, doi:10.1029/2003JC002113, 2004.

Zahibo, N., Pelinovsky, E., Yalciner, A. C., Kurkin, A., Kozelkov, A., and Zaitsev, A.: The 1867 Virgin Island tsunami: observations and modeling, Oceanol. Acta, 26, 609-621, 2003. 